\title{
Variability of currents and vertical stratification in the Marsdiep
}

\author{
J.J. de Vries ${ }^{1}$, H.M. van Aken ${ }^{1}$ and J.J. Nauw ${ }^{1}$ \\ ${ }^{1}$ Physical Oceanography, NIOZ Royal Netherlands Institute for Sea Research, Landsdiep 4, t' Horntje, the Netherlands, \\ jurre.de.vries@nioz.nl
}

\begin{abstract}
Velocity and salinity data is presented from 22 13-hour anchor stations (AS) collected between 2004 and 2011 at different locations in the Marsdiep. For 13 of the 22 AS, the largest velocities occur close to the surface during the entire tidal cycle. For the other 9 AS, a mid-depth velocity maximum is observed during the late flood phase in combination with a vertically stratified water column and strong cross-stream velocities. A mid-depth maximum has only been observed towards springtide conditions. Cross-stream circulation cells with velocities up to $0.4 \mathrm{~m} / \mathrm{s}$ are present during different phases of a tidal cycle together with a vertically stratified water column. Vertical stratification is highly variable within a tidal cycle and seems to be driven by cross-stream circulation patterns. The onset of vertical stratification is during the late ebb (flood) phase and it can persist until the consecutive peak flood (ebb) phase. Stratification is observed just as frequently during springtide as during neaptide conditions. It suggests that changes in fresh water influx are more important for vertical stratification than changes in tidal stirring driven by the spring/neaptide cycle. These observations show that vertical stratification is more frequent and important in the Marsdiep than previously thought.
\end{abstract}

\section{INTRODUCTION}

The Marsdiep is a highly dynamic tidal inlet where the current structure is influenced by a variety of processes. In the past, the water column was always assumed to be mainly well-mixed due to the strong tidal currents up to $2 \mathrm{~m} / \mathrm{s}$ [Postma, 1954; Zimmerman, 1976]. Data on the occurrence of density stratification were, however, lacking. Research of the last decade has shown that stratified conditions can occur [Buijsman and Ridderinkhof, 2008] and according to Groeskamp et al., [2011] they can only occur during slack tides under certain conditions. Strong cross-stream circulation cells may develop during different phases of the tide driven by friction, channel curvature, Coriolis and/or lateral density gradients [Buijsman and Ridderinkhof, 2008].

The main source of fresh water is from the IJsselmeer sluices at Den Oever (DO) and Kornwerderzand (KWZ). All fresh water of $\mathrm{DO}$ and one-third of the fresh water of KWZ is assumed to be transported to the North Sea through the Marsdiep inlet via the Malzwin channel, the southern branch of the Marsdiep channel [Zimmerman, 1976]. The northern branch of the Marsdiep, the Texelstroom channel, is connected to the Vlie channel and the KWZ sluices. The presence of fresh water and differential current shear leads to density fronts, which occur frequently in the Marsdiep and are highly dynamic in time and space.

In this paper, a description of the variability of currents and vertical stratification is presented from data collected between 2004 and 2011 during 22 13-hour anchor stations (AS) in 4 different locations in the Marsdiep (Figure 1).

\section{MEASUREMENTS}

During 13-hours AS, velocity data was collected with a downward-looking shipboard ADCP while remaining at anchor. AS were collected at different locations and during different seasons. During AS28-57, a Nortek was used at a frequency of 1.0 $\mathrm{MHz}$ and with a bin size of $1 \mathrm{~m}$.

During AS28-57, a $1200 \mathrm{kHz}$ RDI workhorse and a bin size of $0.25 \mathrm{~m}$ was used. A 2 ping ensemble was recorded every 2 seconds. The ADCP was located $1 \mathrm{~m}$ below the water level and a blanking distance of $0.5 \mathrm{~m}$ was used. The ADCP was calibrated prior to each AS. Velocity data is corrected for movement and heading of the ship. Velocity output is given in earth coordinates (velocity in east-west, north-south and the vertical direction).

Measurements of salinity and temperature over the entire water column were recorded every 20 minutes during the AS with Seabird Conductivity, Temperature, Depth sensors. The sensors were attached to a metal frame. Velocity and CTD measurement were post-processed and quality controlled.

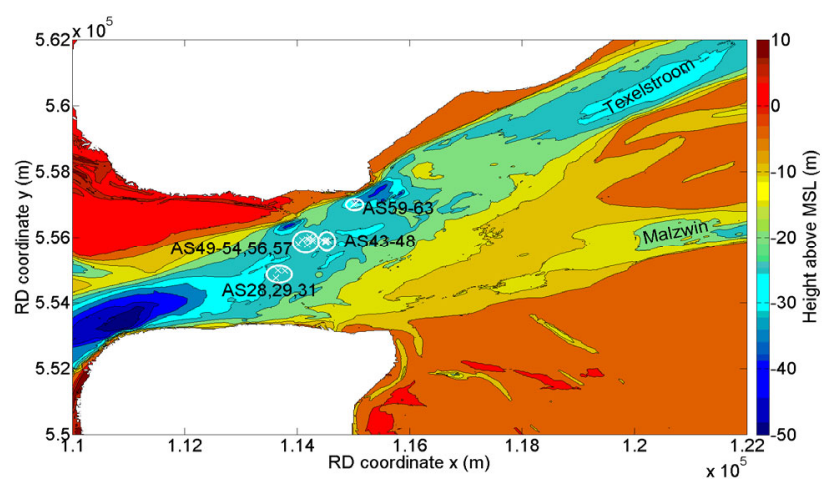

Figure 1. Bathymetric map of the Marsdiep inlet and the bifurcation of the Marsdiep channel into the Texelstroom to the north and the Malzwin channel to the south. The anchor stations are indicated with AS. Four areas are distinguished from southwest to northeast:1) AS28,29,3;2) AS 49-54,56,57;3) AS4348;4) AS59-63 (source: Rijkswaterstaat). 


\section{ANALYSIS}

For each AS, a sine was fitted through the depth-averaged eastwest and north-south velocity with a period of the dominant semidiurnal tidal constituent M2 (12 hours and 25 minutes) using a least-squares method

$u=a_{M 2} \cos \left(\omega t-\varphi_{M 2}\right)$,

where $u$ is the measured depth-averaged flow velocity $(\mathrm{m} / \mathrm{s}), \mathrm{a}_{\mathrm{M} 2}$ is the amplitude of the M2 constituent $(\mathrm{m} / \mathrm{s}), \omega$ is the tidal frequency $(\mathrm{Hz}), \mathrm{t}$ is the time (s) and $\varphi_{\mathrm{M} 2}$ is the phase.

The diurnal inequality and the spring/neaptide modulations are hidden in this signal. The amplitude and phase lag between the east-west and north-south velocities are used to compute the tidal ellipse parameters described in Pawlowicz et al. [2002]. The tidal ellipse parameters are the semi-major axis (SEMA), which is the maximum speed axis of the M2 constituent, the eccentricity (ECC) which is the ratio between the minimum and maximum speed axis. Negative (positive) values indicate (anti-) clockwise rotation. The inclination (INC) is the inclination between the SEMA and the east velocity axis in anti-clockwise direction. The phase (PHA) is the moment (in degrees) during the M2 at which the maximum current speed is reached. The alongstream (primary) and crossstream (secondary) currents are determined by rotating the horizontal velocity vector over INC for each individual AS.

\section{RESULTS}

\section{Tidal Ellipse parameters}

Grouping of the AS in 4 areas shows that the SEMA varies between 1.08 and $1.28 \mathrm{~m} / \mathrm{s}$. The standard deviation of the SEMA of each group is mostly dependent on the range of measurements days along the lunar (read spring/neaptide) cycle. The eccentricity is small at all areas indicating that the tide is almost rectilinear. The inclination varies between 27 and 35 degrees and is dependent on the location of the area and the bathymetry. The orientation of the Marsdiep channel at AS28,29,31 is more east-west than for the other areas resulting in a smaller INC. The bathymetry in the Marsdiep and Texelstroom channel is highly variable which might cause a certain degree of tidal rectification explaining the largest standard deviation in the AS59-63 area. This area is characterized by large depth changes on a small spatial scale. During each AS,

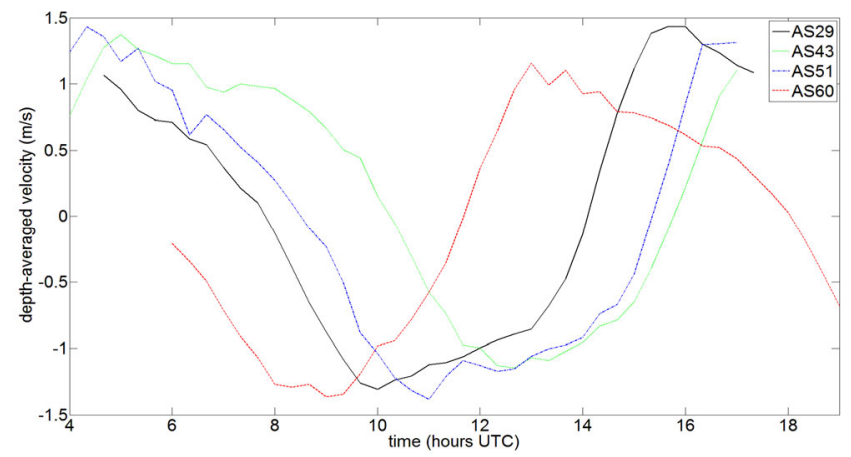

Figure 2. Depth-averaged velocity during AS29,43,51,60.

the measurement location is not exactly the same but describes a loop- 8 kind of pattern around the anchor with an alongstream and cross-stream range of 100 and $50 \mathrm{~m}$ respectively. PHA is between 34 and 315 degrees for the AS. No mean and standard deviation can be calculated from the PHA at each area, since PHA is in degrees/radians. For example, the mean of 0 and 360 degrees, would result in a PHA of 180 degrees, which is a phase error of 180 degrees. The PHA values indicate that the tidal wave is between a progressive and standing wave character. Weather conditions and fresh water influx are neglected from this analysis and require further analysis.

\section{Alongstream and cross-stream velocity}

A general trend of all the AS is that the late ebb phase and slack before flood (SBF) period is shorter than the late flood phase and slack before ebb (SBE) period (Figure 2). This tidal asymmetry is a consequence of the phase difference between the M2 and M4 tidal constituent as already discussed by Friedrichs and Aubrey [1988] and described by Dronkers [1986].

Besides the tidal asymmetry, a characteristic of the alongstream velocity profile is that it seems to have two states. During 13 of the 22 AS, a velocity profile was observed with the largest velocities close to the surface over the entire tidal cycle as exemplified in Figure 3a. Such profiles remind us of the canonical polynomial 'van Veen' profiles. However, during 9 AS, the maximum velocities were observed at mid-depth during the late flood phase (Figure 4a). The difference between the surface

Table 1: Averaged (grey) and standard deviation (white) of tidal ellipse parameters of M2 constituent for each area. Lunar cycle indicate on which days $A S$ were done in the neap/spring cycle with 1 being neap-and 7 being springtide conditions.

\begin{tabular}{|c|c|c|c|c|c|}
\hline Area & depth [m] & lunar cycle & SEMA $[\mathrm{m} / \mathrm{s}]$ & ECC [-] & INC [deg] \\
\hline \multirow[t]{2}{*}{ AS28,29,31 } & 23.30 & 5 & 1.28 & 0.02 & 27.67 \\
\hline & 0.42 & & 0.04 & 0.01 & 1.52 \\
\hline \multirow[t]{2}{*}{ AS49-54,56,57 } & 23.48 & $3,4,6,7$ & 1.23 & 0.02 & 31.84 \\
\hline & 1.25 & & 0.08 & 0.01 & 1.19 \\
\hline \multirow[t]{2}{*}{ AS43-48 } & 23.58 & $1,2,5,6$ & 1.08 & 0.02 & 35.07 \\
\hline & 0.70 & & 0.17 & 0.01 & 0.96 \\
\hline \multirow[t]{2}{*}{ AS59-63 } & 29.52 & 3,4 & 1.16 & 0.02 & 35.17 \\
\hline & 1.42 & & 0.06 & 0.01 & 2.52 \\
\hline
\end{tabular}


velocity and the mid-depth maximum can be up to $1 \mathrm{~m} / \mathrm{s}$. A middepth maximum always coincided with strong cross-stream circulation cells (in northwest direction at the bottom and in southeast direction at the surface) and a strong vertical stratification. AS with a mid-depth maximum flow velocity during the late flood phase has been observed in all areas except the AS28,29,31 area. During the late flood phase of AS28,31, the water column was well-mixed and cross-stream velocities were small. During AS29, the water column was vertically stratified but a strong cross-stream circulation cell (in southeast direction at the bottom and in northwest direction at the surface) only formed around SBE. It is not known if the right conditions do occur at AS29,29,31 for the occurrence of a mid-depth maximum during the late flood phase.

So far, a mid-depth velocity maximum has only been observed towards and during springtide conditions. However, the fresh water influx has been neglected so far. Several longer datasets of flow velocity, surface salinity data and sluice discharge are available which will be used to include the influence of variations in fresh water discharge on the vertical velocity profile. During vertically stratified conditions, strong cross-stream velocities are usually observed during the peak and late phase of flood and ebb (Figure $4 \mathrm{~b}$ ) with velocities up to $0.3-0.4 \mathrm{~m} / \mathrm{s}$.

During well-mixed conditions, cross-stream currents are small or absent (Figure $3 b$ ). The cross-stream circulation cell is generally characterized by southwestward (northeastward) directed surface (bottom) currents. However, cross-stream circulation cells in the opposite direction can also occur (Figure 3b, between 9 and 13 hours UTC).

\section{Vertical stratification}

Vertical stratification is highly variable in time. Vertical

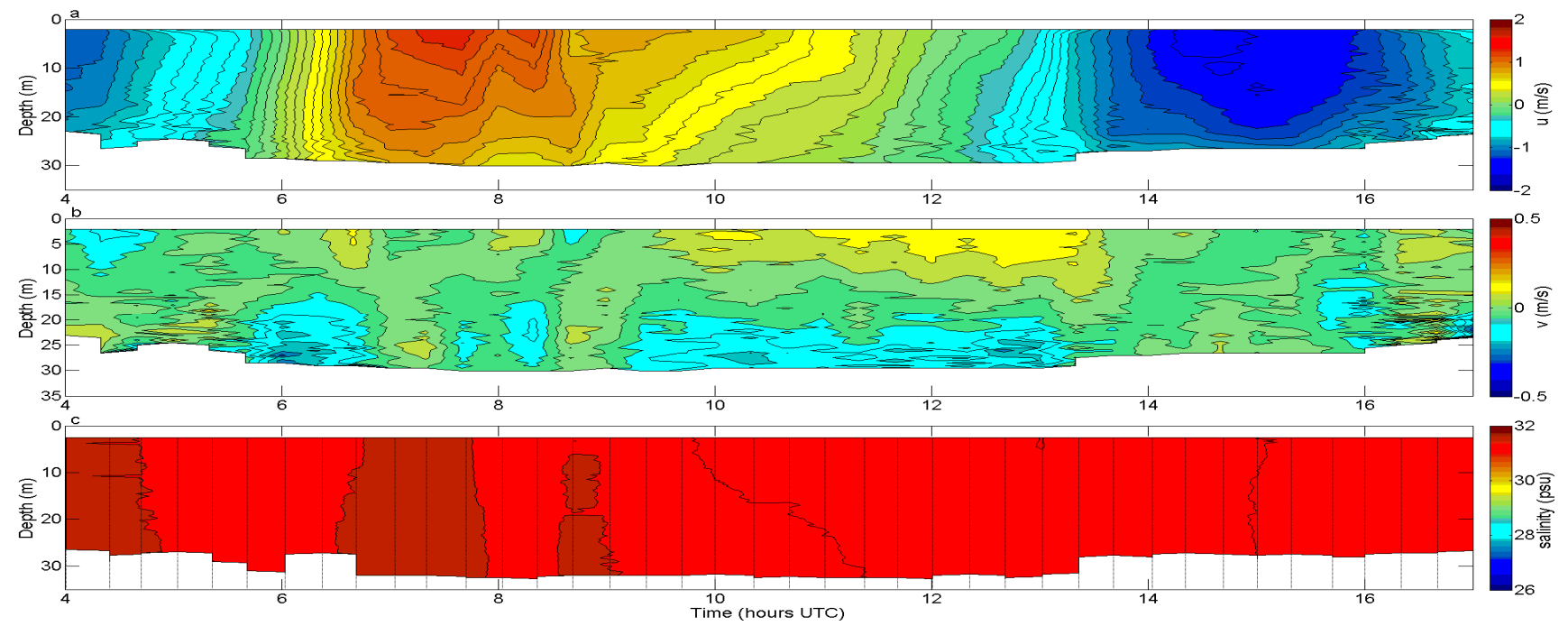

Figure 3. Alongstream (a) and cross-stream (b) velocity and salinity (c) over depth during AS61. Positive (negative) alongstream values are flood (ebb) velocities. Negative (positive) cross-stream values are directed to the southeast (northwest).
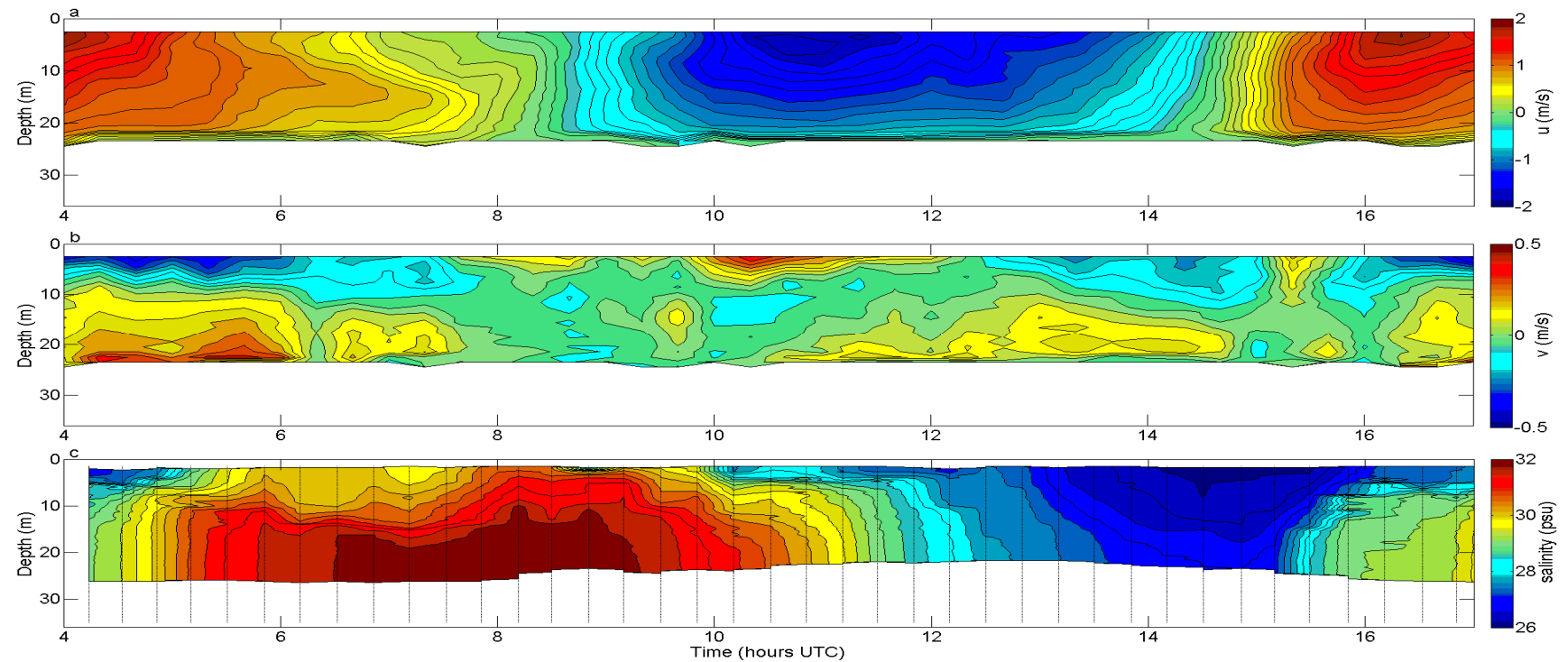

Figure 4. Alongstream (a) and cross-stream (b) velocity and salinity (c) over depth during AS46. 
stratification may already develop during the late flood (ebb) phase and it can persist until the consecutive peak ebb (flood) velocities are reached. Mean bottom to surface salinity differences during an AS are approximately 1 psu, but may increase to 2-4 psu during the late ebb and flood phase and the slack tides. The periodic vertical stratification during SBE and SBF differs in magnitude and duration for each AS. Vertical stratification is always accompanied by strong cross-stream currents. Crossstream currents, driven by lateral density-gradients, channel curvature and Coriolis, change the lateral salinity structure and enable the formation of a vertically stratified water column. It is still an open question what the contribution is of the alongstream and lateral salinity gradient on the generation of vertical stratification. Taking all 4 areas into consideration, it is striking that vertical stratification is observed during neaptide as well as during springtide conditions.

\section{DISCUSSION AND CONCLUSION}

Some interesting features have been observed in the alongstream and cross-stream flow velocity profiles, especially the mid-depth velocity maximum during the late flood phase. A middepth maximum in the alongstream velocity profile during late flood has also been found by Jay and Smith [1990] in the Colombia River Estuary during highly stratified conditions. Geyer [1988 in Jay and Smith, 1990] relates this subsurface maximum to the 'baroclinic forcing in the pycnocline, in combination with weak mixing'. However, the Colombia River Estuary is a highly stratified estuary with a salt wedge, whereas the Marsdiep is classified as a well-mixed estuary which is occasionally weakly stratified [Buijsman and Ridderinkhof, 2008]. The strong lateral baroclinic forcing and the stratified conditions are also present during the late ebb phase, but no mid-depth maximum is observed during any of the 22 AS during the late ebb phase. The tidal asymmetry and the related time period of the late flood and ebb phase might play another important role in the formation of a middepth velocity maximum. To better understand this phenomenon in a periodically stratified basin as the Marsdiep, the mixing characteristics during flood and ebb require more research. A better understanding of the mid-depth maximum is important for the estimation of sediment and nutrient transport in the Marsdiep. The strong circulation cells that occur during the flood and ebb phase are also important for sediment and nutrient transport and are an important agent for lateral transport of salt and heat. The cross-stream circulation cells are driven by lateral density gradients, channel curvature and to a lesser extent Coriolis forcing [Buijsman and Ridderinkhof, 2008]. Via the lateral salt flux, the water column can become vertically stratified if mixing is not too strong. Tidal straining, as described by Simpson et al. [1990] can be another mechanism that drives the generation of vertical stratification. However, the spring/neaptide modulation in vertical stratification as a result of the variation in tidal stirring has not been observed. The relative contribution of the longitudinal and lateral salinity gradients and their relation to stratification requires further research.

The periodic stratification during the slack tides is observed to occur just as frequently during neaptide as during springtide conditions. The asymmetry in the magnitude and duration of the vertical stratification may be of influence to estuarine circulation as described by Geyer et al. [2000], Lerczak and Geyer [2004], Scully et al. [2009] and others. In the Marsdiep, the fresh water influx through the sluices (of which the discharge is only during the ebb phase) is highly variable within a year (Figure 5) from a daily to seasonal timescale. It can result in large variations in stratification, density-driven flows and the alongstream vertical flow profile. The asymmetry in stratification between flood and ebb and their link to the fresh water influx is not investigated yet. Stratification influences the vertical distribution of turbulence, which is important for sediment and nutrient transport [Joordens et al., 2001].

Another complicating factor is that the Malzwin is usually fresher than the Texelstroom during ebb. Besides the AS, longterm velocity data ( 3 times 1 month) is available in combination with surface and bottom temperature and salinity data to further

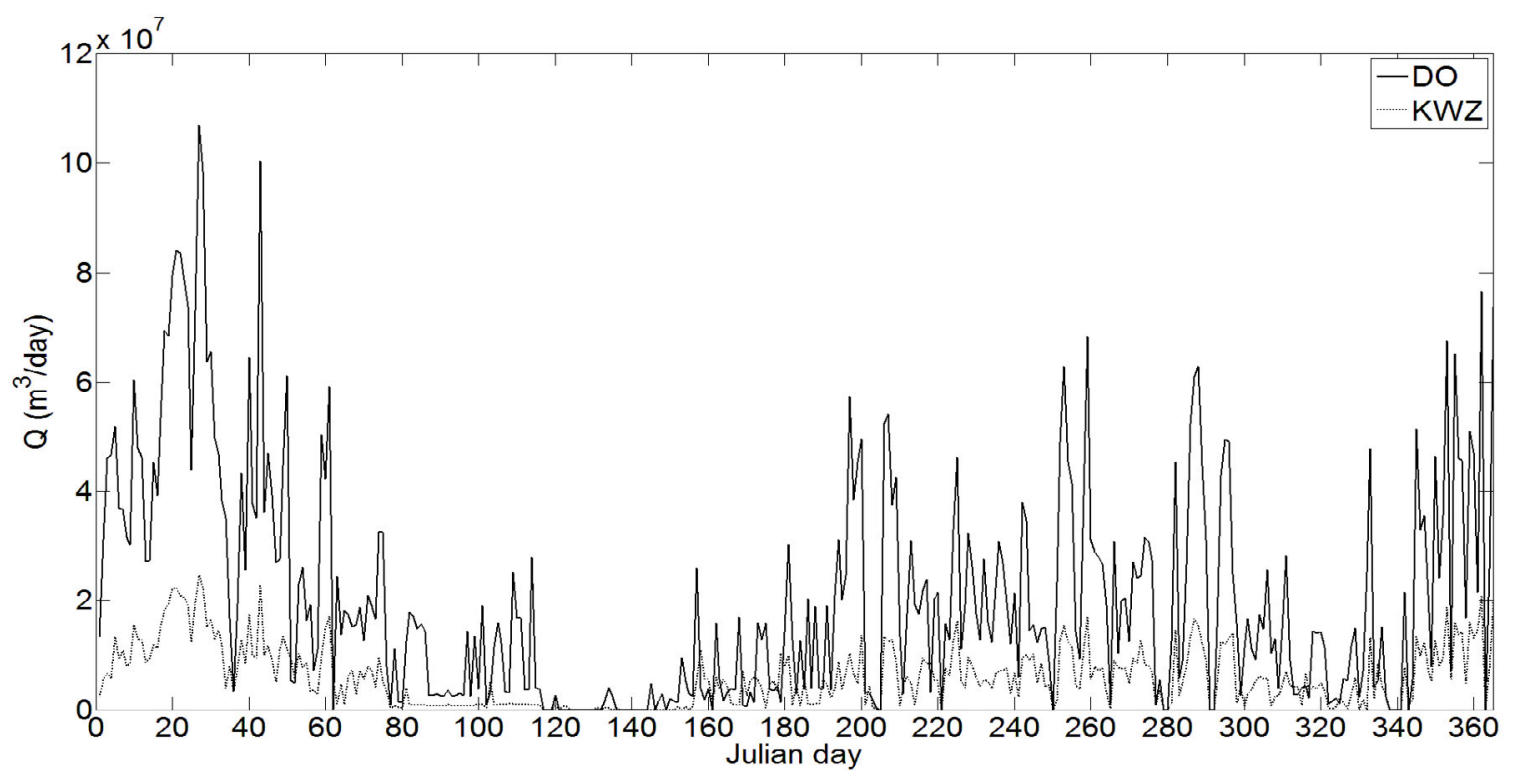

Figure 5. Discharge during 2011 at Den Oever and one third of the discharge at Kornwerderzand which flush into the North Sea through the Marsdiep inlet (source: Rijkswaterstaat). 
investigate the asymmetry in vertical stratification. Also, the General Ocean Turbulence Model (GOTM, see Umlauf and Burchard, [2005] for a review) will be used to further investigate the interaction between the alongstream and cross-stream velocity profile, stratification and fresh water influx.

The influence of wind has been left out so far, but will be studied in the future. Wind contributes to the net subtidal transport [Buijsman and Ridderinkhof, 2007] and may also increase or decrease vertical stratification [Souza and Simpson, 1997].

In this paper, observations of 22 anchor stations in the Marsdiep have shown that the alongstream vertical current structure varies strongly over time with an unexpected mid-depth velocity maximum during the late flood phase when the flow is stratified and strong cross-stream circulation cells are present. Cross-stream currents are highly variable from an intra- to intertidal timescale.

The same is valid for stratification. Stratification occurs during the late ebb and late flood phase and during the slack tides during neaptide and springtide conditions and may persist until maximum current velocities are reached. It is hypothesized that the strong cross-stream circulation cells generate periodical vertical stratification. The interaction of the along-stream, cross-stream velocity profile, stratification, turbulence and the contribution of wind in the Marsdiep will be investigated further over the next years.

\section{AKNOWLEDGEMENTS}

All the students, researchers, technicians and the crew of the research ship Navicula are thanked for their contribution to the data collection in the Marsdiep over the last decade.

\section{REFERENCES}

Buijsman, M.C., H. Ridderinkhof (2007), Water transport at subtidal frequencies in the Marsdiep inlet, Journal of Sea Research, 58, 255-268

Buijsman, M.C., H. Ridderinkhof (2008), Variability of secondary currents in a weakly stratified inlet with low curvature, Continental Shelf Research, 28, 1711-1723

Dronkers, J. (1986), Tidal asymmetry and estuarine morphology, Netherlands Journal of Sea Research, 20, 117-131
Friedrichs, C.T., D.G. Aubrey (1988), Non-linear tidal distortion in shallow well-mixed estuaries: a synthesis, Estuarine, Coastal and Shelf Science, 27, 521-545

Geyer, W.R., J.H., Trowbridge, M.M., Bowen (2000), The dynamics of a partially mixed estuary, Journal of Physical Oceanography, 30, 2035-2048

Groeskamp, S., J.J. Nauw, L.R.M. Maas (2011), Observations of estuarine circulation and solitary internal waves in a highly energetic tidal channel, Ocean Dynamics, 61, 1767-1782

Jay, D.A., J.D., Smith (1990), Circulation, density distribution and neap-spring transitions in the Colombia River Estuary, Progress in Oceanography, 25, 81-112

Joordens, J.C.A., A.J. Souza, A. Visser (2001), The influence of tidal straining and wind on suspended matter and phytoplankton distribution in the Rhine outflow region, Continental Shelf Research, 21, 301-325

Lerczak, J.A., W.R. Geyer (2004), Modeling the lateral circulation in straight, stratified estuaries, Journal of Physical Oceanography, 34, 1410-1428

Pawlowicz, R., B. Beardsley, S. Lentz (2002), Classical tidal harmonic analysis including error estimates in MATLAB using T_TIDE, Computers and Geosciences, 28, 929-937

Postma, H. (1954), Hydrography of the Dutch Wadden Sea, Archive Neerlandais Zoologiques, 10, 405-511

Scully, M.E., W.R. Geyer, J.A., Lerczak (2009), The influence of lateral advection on the residual estuarine circulation: a numerical modeling study of the Hudson River Estuary, Journal of Physical Oceanography, 39, 107-124

Simpson, J.H., J. Brown, J. Matthews, G. Allen (1990), Tidal straining, density currents, and stirring in the control of estuarine stratification, Estuaries, 13, 125-132

Souza, A.J., J.H., Simpson (1997), Controls on stratification in the Rhine ROFI system, Journal of Marine Systems, 12, 311-323

Umlauf, L., H. Burchard (2005), Second order turbulence closure models for geophysical boundary laters. A review of recent work, Continental Shelf Research, 25, 795-827

Zimmerman, J.T.F. (1976), Mixing and flushing of tidal embayments in the western Dutch Wadden Sea, PhD thesis, 1239 